\title{
INSTRUÇÕES ESTRATÉGIAS DE MARKETING IMPULSIONANDO A EXPORTAÇÃO DE SERVIÇOS DO BRASIL: UM ENFOQUE NO SETOR TURÍSTICO
}

\author{
Lorena T. S. da Silva \\ lorena_tss@hotmail.com \\ Gerda L. P. Camelo \\ Professora do Departamento de Gestão, Serviço e Comércio do CEFET-RN \\ gerda@cefetrn.br
}

\section{RESUMO}

O setor de serviços ultimamente tem participação expressiva nas pautas de exportação das mais diversas nações e estados soberanos. O setor de viagens e turismo, em específico, vem a cada dia se consolidando com crescente sucesso e como alternativa à geração de divisas para os lugares que o priorizam ou lhe conferem maior êxito nos investimentos. Sob um prisma de acentuada interação do planeta em virtude da revolução técnicocientífico-globalizacional pela qual passamos, a questão do turismo se constitui como uma atividade muito além de um mero deslocamento por indivíduos ou grupos com fim de conhecer ou visitar novos lugares. Tal ramo abrange variadas nuances as quais implementam o desenvolvimento e a manutenção de sua atividade em si, bem como com outras que mantêm correlações direta e indiretamente. Questões referentes a fatores como estratégia, economia e marketing, por exemplo, também estão intrínsecas ao ramo do turismo nos dias atuais; sendo o enfoque no setor turístico uma exemplificação tangível. Essa monografia tem por objetivos específicos identificar as políticas públicas voltadas para o turismo no Brasil, demonstrar a relevância do turismo na balança de pagamentos, identificar as estratégias de marketing utilizadas no segmento e descrever a importância da Marca Brasil nas exportações de serviço a fim de se alcançar o entendimento do objetivo geral, compreender como as estratégias de marketing alavancam as exportações de serviços. Por meio de pesquisa descritiva exploratória e um aporte teórico, que perpassa por conteúdos atuais da economia e teorias consagradas do marketing, essa monografia tem o intuito de balizar os objetivos contrapondo com a realidade existente e o patamar ideal compreendendo e exaltando a importância do turismo na pauta de exportação da nação e, por conseguinte sua participação na balança de pagamentos.

Palavras-chave: marketing internacional, turismo, exportação de serviços, balança de pagamentos. 


\section{INSTRUÇÕES ESTRATÉGIAS DE MARKETING IMPULSIONANDO A EXPORTAÇÃO DE SERVIÇOS DO BRASIL: UM ENFOQUE NO SETOR TURÍSTICO}

\section{INTRODUÇÃO}

Dentro do cenário da globalização onde as organizações, Estados, nações e economias se vêem cada vez interdependentes e sinérgicas inseridas no mercado internacional que está cada vez mais dinâmico e competitivo, as exportações de serviços podem ser um grande diferencial, uma vez que o cenário internacional aponta para a crescente participação dos fluxos de serviços e uma leve estagnação absoluta da produção de bens.

A importância do setor de serviços requer uma mobilização dos setores público e privado quanto à necessidade de se construir e implementar uma política de exportação de serviços, maximizando a capacidade do segmento para gerar empregos e ampliar a receita cambial; eliminar a vulnerabilidade externa; absorver tecnologias; facilitar investimentos; reduzir custos; difundir a imagem externa; ampliar a capacitação competitiva e outros.

Há uma percepção de que o Brasil possui vantagens comparativas em alguns setores de serviços, como no de viagens/turismo. A exportação de serviços influencia diretamente na balança de pagamentos do país. O Brasil ocupa o $59^{\circ}$ lugar no ranking de competitividade do turismo mundial. O que se pode considerar uma posição aquém do esperado, visto seu potencial.

O setor de turismo nacional defronta-se com importantes limitações, como imagem negativa quanto à segurança; sistemas de informações e de apoio inadequados, inclusive em aeroportos e hotéis; sustentabilidade, entre outros. Tais deficiências apontadas auxiliam na explicação dos motivos que fazem o Brasil ocupar posição modesta, atualmente se posiciona na $59^{\circ}$ em termos de competitividade, em vista da sua potencialidade, no mercado mundial. A fim de minimizar tais pontos negativos o uso dos conceitos de estratégia e marketing pertinentes a tal se, mostra deveras importante.

Segundo o Instituto Brasileiro de Turismo - EMBRATUR (2006) percebe-se que o turismo é fator decisivo para as contas externas de países como México, Espanha, França, Itália e, inclusive, para os Estados Unidos, conquistando importância por sua capacidade de mobilização de fatores de caráter social, econômico e cultural.

A atividade de marketing, segundo Kotler (2000), é um processo social por meio do qual pessoas e grupos de pessoas obtêm aquilo de que necessitam ou desejam com a criação, oferta e livre negociação de produtos e serviços de valor com outros indivíduos. Portanto, no caso dos serviços, envolve a aplicação de um conjunto de conceitos e ações que visam adequar a oferta de prestação de serviços às expectativas do mercado, adequar aos desejos e necessidades dos turistas no caso das viagens/turismo.

O entendimento dos anseios do mercado, a formulação de uma estratégia de marketing tendo como base a definição de um posicionamento claro, consistente e competitivo, a definição de públicos-alvos prioritários e a formatação de campanhas de divulgação utilizando a comunicação integrada de marketing podem contribuir, e muito, para que o desempenho do setor seja mais expressivo e não fique apenas à mercê das variações das condições do ambiente externo. 
Diante disso, o artigo em questão, explanará sobre conceitos e ferramentas de marketing de serviços e turístico -, exportação de serviços e sobre o segmento turístico a partir da indagação: como as estratégias de marketing impulsionam a exportação de serviços do Brasil (enfoque no setor turístico)?

Artigo esse ainda confeccionado a partir de objetivos específicos que depois de esclarecidos se faz de subsidio para a resposta do objetivo geral. Seguindo essa linha lógica os objetivos específicos o qual esse trabalho tem por comprometimento estudar são: identificar as políticas públicas voltadas para o turismo no Brasil, demonstrar a relevância do turismo na balança de pagamentos, identificar as estratégias de marketing utilizadas no segmento e descrever a importância da Marca Brasil nas exportações de Serviço. Sendo o objetivo geral,a razão desse trabalho acadêmico: compreender como as estratégias de marketing alavacam as exportações de serviços do Brasil.

A motivação pra elaboração deste partiu do pressuposto que dentro da ótica atual desenvolvimentista não apenas do País, a exportação de serviços ainda é feita de forma incipiente se comparado com suas potencialidades, lembrando que ela é um dos principais objetos de análise da balança de pagamentos. Dentre os diversos segmentos, o de maior expressão o segmento turístico é o que se destaca tanto no Brasil, mas, principalmente, no nosso Estado.

Caracterizado como a maior atividade do comércio internacional, o turismo triplicou seu tamanho e seu impacto econômico nos últimos cinqüenta anos abrangendo 56 segmentos da economia. Conforme informações do Instituto Brasileiro de Turismo (Embratur - 2006), esse setor movimenta anualmente US\$ 4 trilhões e gera 280 milhões de empregos em todo o mundo.

Em 2007 a entrada de dólares no Brasil, com turistas estrangeiros, bateu recorde com uma alta de $20,39 \%$ na comparação com janeiro de 2006. Tal incremento se deu devido à política de crescente promoção do produto turístico brasileiro. A prioridade dada pelo Governo Federal ao setor com a criação do Ministério do Turismo começou em meados de 2003, época que coube à Embratur a tarefa exclusiva de promover o país no exterior. Com isso, a divulgação internacional do Brasil ganhou planejamento, mais qualidade e passou a atrair mais turistas estrangeiros. Mesmo com essa participação o País ainda tem parcela pouco relevante na comercialização de serviços mundiais, conforme tabela abaixo.

Tabela I: Exportação Mundial de Serviços Comerciais 2005 US\$ bilhões

\begin{tabular}{|l|c|c|}
\hline \multicolumn{1}{|c|}{ Exportação } & Valor & Part. \% \\
\hline Mundo & 2.410 & 100 \\
\hline América do Sul e Central & 68 & 2,8 \\
\hline Mercosul & 23 & 0.95 \\
\hline Outros & 45 & 2,6 \\
\hline Brasil & $\mathbf{1 5}$ & $\mathbf{0 , 6 2}$ \\
\hline
\end{tabular}

Fonte: Bacen (2005)

O aumento dos investimentos estrangeiros no segmento de hotelaria, particularmente na Região Nordeste, reflete essa tendência e pode ser explicado tanto em função do aumento da demanda quanto da melhoria das condições de acesso e infra-estrutura em geral, fatores que influenciam marcadamente a sustentabilidade do fluxo turístico no longo prazo. As condições internacionais também são atualmente bem favoráveis; dados da Fundação 
Getulio Vargas (FGV-2006) revelam número recorde de turistas circulando no planeta em 2006: 808 milhões, que representam 5,5\% de incremento em comparação com 2004.

A pesquisa exploratória descritiva refere-se ao levantamento de dados com mais profundidade de determinados parâmetros sob os aspectos que interessam já preestabelecidos no diagnóstico. A pesquisa tem abordagem interpretativa de processo contínuo, pois segundo Marconi (2004), propicia a estratégia escolhida, pois busca no campo uma relação mais estreita com a realidade a ser estudada. Neste caso identificando os fatores que contribuem para a sua inserção efetiva do Brasil como exportador de serviços. Considerada bibliográfica já que se faz uso de material já publicado. Sendo de fonte primária os dados originados de órgãos públicos que dispõem de algumas informações relevantes para os estudos de Comércio Internacional, como os Órgãos Intervenientes no mesmo, SECEX - Secretaria do Comércio Exterior, MDIC - Ministério de Desenvolvimento Internacional e Comércio, Ministério do Turismo e outros. ( LAKATOS: 1996).

\section{FUNDAMENTAÇÃO TEÓRICA}

\subsection{Exportação de Serviços}

É de consciência geral que o Brasil possui predominância nas mercadorias, principalmente commodities, nas exportações desde sua colonização até os dias atuais. Segundo o Bando do Brasil (2006) a exportação de serviços em termos absolutos vêm se tornando mais significante. Ela merece destaque por se tratar da modalidade que proporciona excelentes ganhos cambiais ao País exportador, além de constituir uma oportunidade para venda paralela de bens e mercadorias.

Para Carvalho (2004), “serviço pode ser definido como qualquer ato ou desempenho que uma parte possa oferecer e que seja essencialmente intangível e não resulte na propriedade de nada. Sua produção pode ou não estar vinculada a um produto físico. Assim, uma oferta de uma empresa ao mercado inclui alguns serviços”.

Reduções no custo de transportes, novas tecnologias em telecomunicações e informática e marcos regulatórios menos restritivos são alguns dos fatores para a crescente importância das exportações de serviços no comércio mundial.

Para Ratti (2001) o balanço de pagamentos pode ser estruturado com os seguintes itens: transações correntes, transferências unilaterais e movimentos de capitais.A soma da balança de comercio e da balança de serviços irá dar origem à balança de transações correntes, a qual constitui na maioria dos casos, a principal parte do balanço de pagamentos.

A partir dessa breve estruturação comprova-se a magnitude da relevância dos serviços na economia do País. O Brasil com seu objetivo desenvolvimentista não esta isento de esforços para maximizar esse âmbito, embora seja fato a discrepância entre as contas que coexistem na balança de pagamentos.

O tema vem ganhando cada vez mais espaço nas pautas desenvolvimentistas do governo brasileiro. Prova disso aconteceu durante o $26^{\circ}$ ENAEX onde foi anunciado um sistema de registro de serviços a partir do próximo ano, denominado Siscoserv. 
O setor de serviços, na atualidade, se apresenta com crescente vigor e dinamismo nas economias por ser o segmento determinante na sustentação do crescimento econômico; preponderante na participação e crescimento da renda e principal gerador de empregos. Isso é verdadeiro, tanto para os países desenvolvidos como para os em desenvolvimento, como o Brasil.

Nos países desenvolvidos, devido à limitação na possibilidade de expansão "horizontal” da produção de bens, o crescimento fica fortemente dependente da incorporação de novas tecnologias, saltos na produtividade, fusões de empresas e inserção e maior integração das economias. Esses procedimentos implicam dispensa de mão-de-obra que, em sua grande maioria, é absorvida pelo setor de serviços. Essa é a razão principal de os países desenvolvidos pressionarem por maior abertura de mercados externos para as suas exportações nessa área.

\subsection{Políticas Públicas Direcionadas ao Turismo}

Dentre os vários ramos da exportação de serviços o de viagens está dentre os mais relevantes, em termos de fluxo de capital e, por conseguinte representatividade nos mercados e nas balanças de pagamento de diversos países. Segundo a EMBRATUR (2006) o principal objetivo das viagens é o turismo (57\%).

O turismo brasileiro apresentou no primeiro quadrimestre de 2007 um marco histórico no volume de receitas cambiais com gastos de turistas estrangeiros: o primeiro trimestre alcançou US\$ 1,332 bilhão. Isso representa 9,7\% a mais, comparado ao mesmo período de 2006. A corrente cambial turística também se destacou neste primeiro trimestre de 2007 com um total de US\$2,925 bilhões, $18,9 \%$ a mais do que o registrado nos três meses iniciais de 2006.

Evidencia-se, assim, a importância do turismo na economia da nação, porém grande parte do desenvolvimento desse segmento independe da iniciativa/sociedade privada. O grande impulsionador do desenvolvimento desse segmento é o Estado.

As Políticas Públicas compreendem as decisões de governo em diversas áreas que influenciam a vida de um conjunto de cidadãos. São os atos que o governo faz ou deixa de fazer e os efeitos que tais ações ou a ausência destas provocam na sociedade.

Segundo o SEBRAE (2007) a atividade de turismo foi eleita uma das prioridades da Administração Pública brasileira. Dados atualizados do MDIC demonstram que no Brasil, o turismo representa menos que 5\% do Produto Interno Bruto (PIB), enquanto a média mundial é em torno de $10 \%$. A atividade de turismo foi eleita uma das prioridades da Administração Pública brasileira, isso dá a dimensão da importância do setor e de como ele pode influir no desenvolvimento do país.

As administrações ou organizações nacionais de turismo, sejam órgãos públicos ou associações privadas, ajudam a prover e monitorar o desenvolvimento do turismo dentro do país, ao passo que organizações estaduais promovem e definem o crescimento em uma área de menos escala, em parceria com organizações internacionais na busca da remoção de barreiras e promoção dos diversos destinos. 
O Ministério do Turismo em parceria com a EMBRATUR desenvolve sete Macroprogramas estratégicos, fruto do Plano Nacional de Turismo - 2003 que vão desde a melhoria da infra-estrutura até a promoção e apoio a comercialização. Dentro desses, desdobra-se vários programas que, por conseguinte, buscam seus objetivos através de diversas ações cujo detalhamento não é pertinente.

Na ocasião da criação do PNT foi diagnosticado que o Brasil, apesar dos avanços obtidos nos últimos anos, está longe de ocupar um lugar no cenário turístico mundial compatível com suas potencialidades e vocações. A falta de articulações entre os setores governamentais tem gerado políticas desencontradas, fazendo com que os parcos recursos destinados ao setor se percam em ações que se sobrepõem ou que não estão direcionados para objetivos comuns. Ao traçar as metas e objetivos o Governo espera até 2008 gerar oito bilhões de dólares em divisas. (EMBRATUR :2006)

Os macro-programas são divididos de acordo com as finalidades a seguir: gestão e relações institucionais, fomento, infra-estrutura, estruturação e diversificação da oferta turística , qualidade do Produto Turístico, promoção e apoio a comercialização.

\subsection{Marketing}

O conceito moderno formatado por Kotler, indica que o "marketing é o conjunto de atividades que tem por objetivo a facilidade de trocas"; as atividades mercadológicas projetam-se sobre outros campos das relações sociais, como instituições culturais, cívicas e outras. (VAZ: 2003)

Essa definição é baseada nos conceitos centrais, tais como necessidades, desejos e demanda; produtos como bens, serviços e idéias; valores, custos e satisfação; trocas e transações; relacionamentos e redes; em mercados (mercado-alvo e segmentação) e principalmente em empresas e consumidores; o marketing, segundo Kotler (2005, p.30), é exposto como: “(...) um processo social e gerencial pelo qual indivíduos e grupos obtêm o que necessitam através da criação de oferta e troca de produtos de igual valor”. Uma organização que deseja obter as respostar previstas de seus mercados-alvo deve utilizar de diversas ferramentas. Essas ferramentas constituem o mix de marketing ou composto de marketing. Segundo Kotler (2005, p. 37): “o mix de marketing é o conjunto de ferramentas de marketing que a empresa utiliza para perseguir seus objetivos de marketing no mercadoalvo".

Essas ferramentas são classificadas em quatro grupos amplos, denominados os 4Ps do marketing: produto, preço, praça (ou ponto-de-venda) e promoção.

De acordo com a OMT (2003) com a concorrência cada vez maior na indústria turística, à medida que novos destinos são desenvolvidos, aqueles que contam com planos de marketing vão ter um desempenho superior aos que não têm, e a formulação dessas diretrizes costuma ser de responsabilidade da administração turística nacional.

\subsection{Marca Brasil}

Marca é um importante instrumento na política de comercialização. Ela promove o fortalecimento da imagem É o nome, um símbolo que serve para distinguir os 
produtos/serviços de uma organização. Podendo ser um ou mais elementos distintos, letras, desenhos, combinação de cores ou até um sobrenome.(MINERVINI:2001)

A presença prolongada na memória coletiva faz com que as pessoas já associem aos nomes certos valores, impressões e referências, gerando aquilo que tecnicamente denominamos "imagem de marca”, ou "conceito de marca".

Se uma marca turística e sua imagem mercadológica são positivas, o esforço de marketing poderá iniciar diretamente pela intensificação dos apelos publicitários e ações promocionais. (VAZ: 2003)

A Marca Brasil não se resume a um simples logotipo ou a uma ação isolada, ela é resultado do Plano Aquarela. Iniciado em meados de 2004 que tem como meta inserir o Brasil como um dos 20 maiores destinos de turismo do mundo até o fim de 2007, com o objetivo de criar uma identidade visual permanente para o país.

\section{INTERPRETAÇÃO DOS DADOS}

\subsection{Demonstração da Importância do Turismo na Balança de Pagamentos}

A Balança de Pagamentos nacional que demonstra a contabilização das transações do Brasil com o resto do mundo, atualmente apresenta saldo positivo. O que vem garantindo esse saldo é o superávit comercial, proveniente do aumento da demanda pelos produtos principalmente commodities - vastos no Brasil, somado à crescente política de incentivo as exportações. Essa política pode ser exemplificada pelos incentivos fiscais aos exportadores e pelo investimento em infra-estrutura de escoação.

Esse contexto subentende uma situação confortável do País quanto suas transações correntes, porém a realidade é outra. Baseando-se em dados da AEB (2006) desde 2004 apesar do saldo das transações totais terem expandido $223.9 \%$ o déficit da conta de serviços cresceu em ritmo preocupante, $90.8 \%$.

Como a balança de pagamentos é formada pelas transações correntes, transações unilaterais e movimentos de capitais; e sendo a conta de transações correntes constituída pela comercialização de mercadorias e serviços, ou, pela balança comercial e balança de serviços respectivamente, entende-se que tal déficit na conta de serviços requer um volume de mercadorias muito mais alto a ser exportado para que a balança de pagamentos mostre superavitária, devido ao alto valor agregado dos serviços.

A exportação de serviços é tipicamente desenvolvida por países já desenvolvidos. Segundo dados do MDIC (2007) o comércio de serviços mundial é concentrado $75 \%$ do seu montante nas nações desenvolvidas. Os países desenvolvidos pela sua "limitação" da possibilidade de expansão "horizontal" na produção de bens, assim essas nações tem seus esforços voltados para abertura de mercados nessa área.

Seguindo a lógica dos três grandes agregados: transporte, viagens e outros serviços como software e construção. Segundo o MDIC(2007) o Brasil tem como saída para o déficit na conta de serviços o investimento no turismo, que está dentro do agregado de viagens e concentra a maior parte dos negócios mundiais, além de ser o segmento no qual o País tem muito potencial. 
A visão tradicional de que o turismo é uma atividade a ser empreendida na ausência de alternativas econômicas, como uma espécie de prêmio de consolação às regiões mais exóticas do planeta, não poderia estar mais distante da realidade. Em um país como o Brasil, o turismo constitui um dos segmentos essenciais de uma estratégia bem-sucedida de desenvolvimento.

O turismo é um segmento que gera ingresso de divisas trazidas pelos turistas estrangeiros e, sobretudo investimento externo, principalmente no setor de infra-estrutura. A mudança do regime cambial, aliada às políticas modernizadoras no setor impulsionam seu crescimento.

Segundo a EMBRATUR (2006) a importância dessa atividade é cabal na geração de divisas para um país que necessita anualmente de aproximadamente US $\$ 40$ bilhões para equilibrar sua balança de pagamentos e gerar pelo menos um milhão de novos empregos.

Conforme se pode constatar na figura a seguir, a corrente cambial turística (receita mais despesa) é deveras importante na balança de pagamentos nacional, sendo o segmento turístico um dos maiores agregados e termos de valor comercializados( exportados).

Figura I: Arrecadação das Exportações

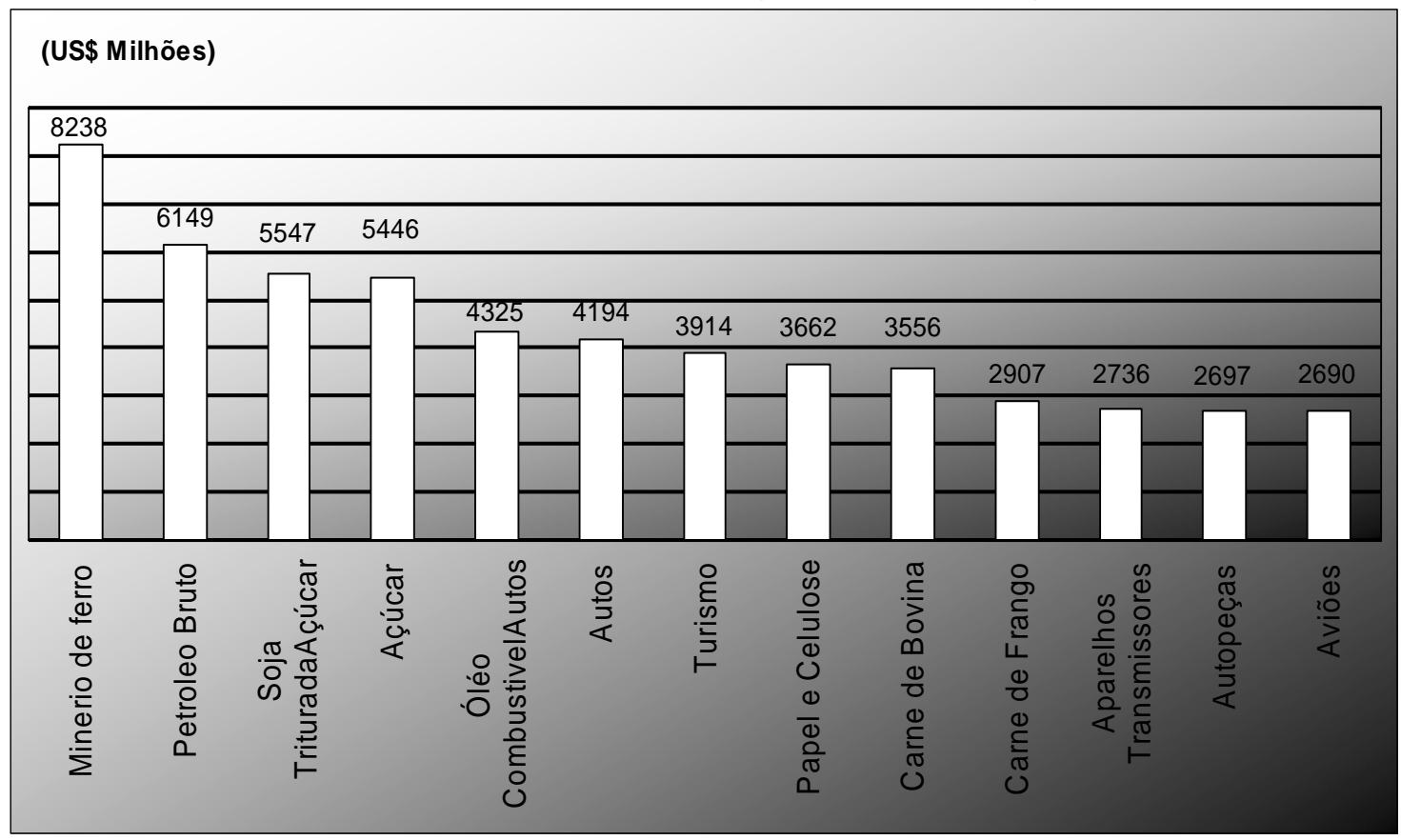

Fonte : Construção do Autor, a partir de SEBRAE (2007)

\subsection{Políticas Públicas}

Partindo do princípio de que o grande impulsionador do segmento turístico é o Estado. As decisões e ações do governo configurando um compromisso público que visa dar conta de 
determinada demanda, em diversas áreas expressando a transformação daquilo que é do âmbito privado em ações coletivas no espaço público, ou seja, as políticas públicas se mostram como ferramental fundamental para o desenvolvimento do segmento.

Nesse contexto o Brasil tem se mostrado deveras atuante. O turismo, visto sua importância na balança de pagamentos e assim da economia como um todo, tem ocupado bastante espaço na pauta desenvolvimentista do Governo.

Isso é comprovado pela criação do Ministério do Turismo em 2003 e a determinação da atuação da EMBRATUR apenas na promoção dos serviços turísticos brasileiros. A partir dessa criação, na verdade transferência já que ele era vinculado MDIC, o País otimizou a concepção, condução e gerenciamento das políticas públicas, orientado por um pensamento estratégico de crescimento econômico.

O crescimento contínuo desse segmento se dá pelo conjunto de políticas de incentivo por parte do Governo desde 2003. Data que coincide, como dito anteriormente, com a criação do Ministério do Turismo e com o Plano Nacional de Turismo. Ele se faz operacionalizar por macro-programas, programas e ações.

A nível nacional os programas, pelo menos em teoria, se mostram bem estruturados e com metas sensatas. Os macro-programas que abrangem desde a infra-estrutura de recepção e deslocamento dos turistas até estratégias de promoção do ‘destino’ no mercado exterior.

No âmbito Brasil, principalmente os programas de divulgação: programa nacional de promoção nacional e internacional, programa de posicionamento da imagem Brasil e o programa de apoio à comercialização mostram-se eficazes e eficientes. Esses somados às ações dentro do PPA estão proporcionando o crescimento do market-share turístico.

\subsection{Estratégias de Marketing Pertinentes}

As estratégias de marketing têm se mostrado um instrumento de grande valor para promover a alavancagem do turismo internacional e como conseqüência melhora no saldo da balança de pagamentos.

No âmbito das iniciativas públicas o Governo demonstra maturidade para desenvolver as ações de marketing. Com a criação do Ministério do Turismo e conseqüente concepção do Plano Aquarela enfim o País parece entender a importância da definição da imagem própria e do público-alvo.

Para realizar o processo de planejamento do Marketing Turístico, é necessário fazer algumas analogias. Partiu-se do produto, quando ele é promovido fora da sua localidade e se converte em uma oferta. A oferta é um produto promovido mediante programas de atuações de comercialização, venda e comunicação, dirigidas tanto ao público profissional, o chamado "trade turístico", como ao turista potencial, ou consumidor. Uma Oferta Turística é, então, um produto turístico promovido através das redes de venda e/ou de comunicação turística. O público, atraído pelo produto e por sua oferta, efetua o consumo turístico. Entende-se consumo turístico a realização por parte do público consumidor da atividade proposta no produto: visitar, passear, comer, comprar, assistir, praticar esportes, etc. 
Agindo em concomitância com os programas do macro-programa de promoção e apoio à comercialização (supracitados) o Plano Aquarela é uma exemplificação clara do bom uso dos conceitos e ferramentas do marketing.

Partindo da compreensão primordial dos conceitos básicos do marketing como: desejos, mercado-alvo, segmentação e imagem. O Plano iniciou suas atividades com uma análise de mercado que se baseou em mais de 6000 entrevistas com turistas de 18 mercados considerados prioritários para o Brasil, assim praticando a segmentação de mercado, a EMBRATUR traça seu mix de mercado adequando seu serviço/produto.

A análise das respostas resultou na imagem que o estrangeiro tem do país. Como aspectos positivos foram citados os recursos naturais, a diversidade cultural e a hospitalidade do brasileiro, entre outros (daí a escolha da imagem da aquarela, em que cada cor simboliza uma dessas qualidades). Entre os aspectos negativos foram mencionados a imagem estereotipada, o desconhecimento, a falta de segurança e o papel da mídia na construção da imagem do país.

Feito esse diagnóstico, a estratégia adotada pelo Plano Aquarela foi dividir os turistas potenciais em cinco grupos de interesse: sol e praia, ecoturismo, cultura, esportes e negócios e eventos. O passo seguinte consistiu em oferecer informações e produtos sobre 86 roteiros que envolvem 163 destinos brasileiros, conforme o perfil do consumidor.

Demonstrando assim que o serviço comercializado mesmo com sua característica de intangibilidade agrega valor, devido a todos os programas de comercialização e promoção evidenciando a orientação tanto para o marketing como para o 'produto turístico'.

Um ponto importante a ser destacado é a questão da rede de relacionamentos que se criou, dentro do programa de marketing de relacionamento através de envios de e-mails e malas diretas para turistas cadastrados no site da EMBRATUR ou credenciados às agências de viagens, além da aproximação física através de feiras e salões de negócios.

\subsection{Relevância do uso de uma Marca}

O turismo constitui um espaço privilegiado de marketing do país e de seus produtos, fortalecendo aquilo que é genericamente chamado de "Marca Brasil".

A Marca Brasil que foi 'concretizada' no Plano Aquarela constitui um importante instrumento de comercialização do serviço turístico. O uso de imagens relacionadas a países vem de longa data. Vários roteiros turísticos já divulgavam sua imagem através de logotipos. Com o uso da mesma não só segmento turístico é beneficiado bem como qualquer produto advindo do Brasil. A marca é incorporada a alguns produtos quando vão ser exportados, fincando assim a imagem à idéia.

Marca Brasil foi confeccionada a partir das idéias que os entrevistados tinham do Brasil, segundo eles o: verde significa as florestas; amarelo o sol e luminosidade; vermelho e laranja as manifestações populares; o azul o céu e a água; e o branco das manifestações religiosas. Confirmando-se como importante instrumento na política de comercialização, promovendo o fortalecimento da imagem

A presença prolongada na memória coletiva faz com que as pessoas já associem aos nomes certos valores, impressões e referências, gerando aquilo que tecnicamente denomina-se "imagem de marca", ou "conceito de marca". Segundo a APEX (2007) houve um incremento da comercialização desde a implantação da marca e ações vinculadas a mesma. 
Um ponto interessante é manutenção da identidade, devido à exaltação das cores que os turistas pesquisados achavam características do País, bem como a manutenção do nome em Português.

Esse incremento pode ser explicado pelos benefícios que uma marca forte traz ao produto ou serviço. Primeiramente o posicionamento onde segundo a pesquisa do Plano Aquarela define o Brasil como destino onde se destaca o 'estilo de vida' e 'patrimônio cultural'. Cria-se assim estabilidade, demonstrando a capacidade de ser ponto referencial, farto esse atestado pelo alto índice de recomendação das turistas que ao Brasil já vieram, além do fator suporte dado à continua promoção da marca nos mercados-alvos.

\section{CONSIDERAÇÕES FINAIS}

Ao se formular todos esses pontos tem-se aporte para entender o quão o marketing é importante na alavancagem das exportações de serviços do Brasil. Primeiramente após perceber a magnitude dos serviços nas contas do Brasil, que ainda é totalmente dependente da frente às variações na economia mundial justamente pelo patamar incipiente de exportações de serviços, os grandes agregados, comprovados pelos seguidos déficits no saldo de serviços. Percebeu-se a fragilidade e o não dinamismo do terceiro setor no Brasil.

Em seguida a evidenciação por dados que o turismo - dentro de viagens - além de ser o agregado mais lucrativo entre os serviços, é o que o Brasil melhor pode se destacar visto suas potencialidades naturais. Porém, visto em comparação com outros países que não apresentam tantos atrativos ele ainda ocupa posição modesta.

O setor de turismo nacional se defronta com importantes limitações, como a imagem negativa quanto à segurança e apoio inadequados (inclusive aeroportos e hotéis) sustentabilidade e outros. Esses aspectos negativos podem ser amenizados com o auxilio de ações no campo do marketing, especialmente em relação ao processo de divulgação/promoção.

O contexto que se vislumbra é de um futuro mais atraente. Nos últimos anos evidenciouse um incremento da entrada dos turistas no País. Essa nova realidade não imerge do acaso, através de políticas publicas mais presentes, em meados de 2003, com a criação de um Ministério para o turismo e ação intensa do Governo, o Brasil vem galgando mais posições no ranking de destinos mais procurados. Tal preocupação entrou na pauta desenvolvimentista no país.

Tais políticas são bem abrangentes passam pela construção de infra-estrutura de acomodação e transporte, fomento, qualidade do serviço, promoção, informações e relações internacionais. Dentro das políticas de apoio e promoção encontraram-se vários programas que estão ligados intrinsecamente ao marketing, sendo essas com o maior impacto e visibilidade positiva. As organizações que pretendem crescer ou mesmo fixar sua fatia de mercado (market-share) precisam se comunicar com as partes interessadas e seu público-alvo. Para tanto é importante ter a consciência do que dizer, para quem dizer e com que freqüência fazê-lo. Vários conceitos são percebidos e usados a favor desses programas. Exemplos desses conceitos que os programas usam muito bem são: posicionamento, valor, relacionamento, idéia, imagem, troca, segmentação, analise e pesquisa ambiental, comunicação e propaganda. 
De acordo com a OMT (2003) com a concorrência cada vez maior na indústria turística, à medida que novos destinos são desenvolvidos, aqueles que contam com planos de marketing vão ter um desempenho superior aos que não têm, e a formulação dessas diretrizes costuma ser de responsabilidade da administração turística nacional.

A elaboração de planos de negócios, para potencializarem suas perspectivas de sucesso, devem necessariamente reforçar seu comprometimento com os mercados que pretendem atingir, de forma assertiva e competitiva.

O plano mais bem sucedido do histórico do setor de serviços é o Plano Aquarela, onde destacou-se 18 mercados prioritários para o Brasil, entre eles nações da América do Sul, Europa, América do Norte e Oriente e também os principais motivos pelos quais os turistas vêm ao território brasileiro: sol e praia; ecoturismo; cultura; negócios e eventos; e esportes.A nova estratégia aplicada é vender o Brasil como um todo, como uma marca forte, com a capacidade de solidificar o marketing de produtos e serviços não apenas de turismo, mas de outros segmentos.Anteriormente a esta estratégia, as regiões brasileiras vinham sendo promovidas separadamente. A ênfase dada à informação, principal fraqueza do país na área turística. Percebeu-se que a imagem estereotipada que disseminada exaustivamente em outras épocas, já não surtia o efeito desejado. Para reverter este quadro, o posicionamento adotado foi o de destacar as belezas naturais e o estilo de vida singular do brasileiro. Somado a isso com a criação da Marca Brasil ocorreu valorização deste ideal, de forma a definir todas as características do país, colaborando na divulgação de uma imagem forte.

Conclui-se que nas atuais perspectivas com o incremento do setor turístico por meio de ações de marketing, principalmente por ferramentas promocionais, as estratégias de marketing tem papel fundamental para o aumento da comercialização de serviços a nível internacional, facilitando o saldo das transações correntes e, por conseguinte alcançando taxas mais expressivas na balança de pagamentos.

\section{REFERÊNCIAS}

APEX Brasil. Agência de Promoção de Exportações e Investimentos. Disponível em: $<$ http://www.apexbrasil.com.br/> . Acesso em: 15 nov 2006.

ASSOCIAÇÃO DE COMÉRCIO EXTERIOR DO BRASIL. Disponível em: < http://www.aeb.org.br/> , acesso em: 20 out 2006.

BANCO DO BRASIL. Informe Comercio Exterior. Disponível em: <http://www.bb.com.br/appbb/portal/on/intc/mpe/index.jsp/>. Acesso em: 25 abr 2007

CERTO, Samuel C.; PETER, J. Paul. Administração Estratégica: planejamento e implantação da estratégia. São Paulo: Makron Books, 1993.

CHIAVENATO, Idalberto. Introdução à teoria geral da administração. 6. ed. Rio de Janeiro: Campus, 2000.

EMBRATUR, Portal Brasileiro do Turismo, Disponível em:<http://www.braziltour.com.br/>, Acesso em: 01 nov 2006. 
ETZEL, Michael J.; WALKER, Bruce J.; STANTON, William J. Marketing. São Paulo: Editora Makron Books Ltda, 2001.

FUNDAÇÃO GENTULIO VARGAS. Disponível em: <http://www.fgv.br/> Acesso em: 05 abr 2007

BRASIL GOVERNO FEDERAL, Republica Federativa do Brasil. Disponível em : <http://www.brasil.gov.br/>, Acesso em: 15 Abr 2007.

IBGE, Instituto Brasileiro de Geografia e Estatística. Disponível em: <http://www.ibge.org.br/>, Acesso em: $10 \mathrm{Abr} 2007$

KOTLER, Philip. Administração de Marketing: Edição do Milênio. São Paulo: Prentice Hall, 2000.

LAKATOS, E. M. ; MARCONI M. de A. Fundamentos da Metodologia Científica. 3 ed. São Paulo: Editora Atlas, 1996.

MINERVINI, Nicola. O exportador. 3 ed. São Paulo: Makron Books, 2001.

Ministério do Desenvolvimento Industria e Comércio Exterior. Disponível em: $<$ http://www.desenvolvimento.gov.br/> , Acesso em: 20 out 2006

MINISTÉRIO DO TURISMO BRASIL, Dados e Fatos do Ministério do Turismo. Disponível em: <http://www.institucional.turismo.gov.br/> . Acesso em: 05 de mar 2007

MOTA, Kleila Cristina Nicolau. Marketing Turístico Promovendo uma atividade Sazional. 1 ed. São Paulo: Atlas, 2003.

O GLOBO ON-LINE, Ranking de Competitividade do Turismo Mundial - World Economic Fórum Disponível em: <http://www.oglobo.globo.com/viagem/mat/2007/03/02/294771276.asp/>. Acesso em: 01 mai 2007.

OMT. Turismo Internacional: uma Perspectiva Global. 3 Ed. Porto Alegre: Bookman, 2005

RATTI, Bruno. Comércio internacional e câmbio. 10 ed. São Paulo: Aduaneiras 2003

SOUZA, Silvio R. S. de. Técnicas de Pesquisa em Administração. Alvorada: [s.n.]: 2005

SEBRAE, Serviço Brasileiro de Apoio às Micro e Pequenas Empresas. Disponível em: < http://www.sebrae.com.br/> , Acesso em: 02 mar 2007.

VERGARA, Syllvia Constant. Projetos e Relatórios de Pesquisa em Administração Atlas: São Paulo, 1997.

VAZ, Gil Nuno, Marketing Institucional: O Mercado de idéias e imagens. São Paulo: Pioneira, 2003. 